\title{
Suicide and no axis I psychopathology
}

Carl Ernst ${ }^{1}$, Aleksandra Lalovic ${ }^{1}$, Alain Lesage ${ }^{1,2}$, Monique Seguin ${ }^{1,3}$, Michel Tousignant ${ }^{1,3}$ and Gustavo Turecki*1

\begin{abstract}
Address: ${ }^{1}$ McGill Group for Suicide Studies, Douglas Hospital Research Centre, McGill University, Montreal, Canada, ${ }^{2}$ Department of Psychiatry, University of Montreal, Montreal, Canada and ${ }^{3}$ University of Quebec, Montreal, Canada

Email: Carl Ernst - cp_ernst@yahoo.ca; Aleksandra Lalovic - aleksandra.lalovic@mail.mcgill.ca; Alain Lesage - alesage@ssss.gouv.qc.ca; Monique Seguin - monique.seguin@uqo.ca; Michel Tousignant - tousignant.michel@uqam.ca; Gustavo Turecki* - gustavo.turecki@mcgill.ca

* Corresponding author
\end{abstract}

Published: 30 March 2004

BMC Psychiatry 2004, 4:7
Received: 23 December 2003

Accepted: 30 March 2004

This article is available from: http://www.biomedcentral.com/I47I-244X/4/7

(C) 2004 Ernst et al; licensee BioMed Central Ltd. This is an Open Access article: verbatim copying and redistribution of this article are permitted in all media for any purpose, provided this notice is preserved along with the article's original URL.

\begin{abstract}
Background: It is unclear why approximately $10 \%$ of suicide completers seem to be psychiatrically normal. To better understand this issue, we studied suicide completers without an axis I diagnosis and compared them, on measures of psychopathology other than axis I, to normal controls and suicide cases with axis I psychopathology.
\end{abstract}

Methods: 168 suicide cases were examined by way of a psychological autopsy with the best possible informant. Sixteen cases did not meet criteria for an axis I diagnosis; each of these cases was then age and gender matched to 52 suicide completers with an axis I disorder and I I 0 normal controls.

Results: Fourteen of sixteen suicide cases without an axis I diagnosis had detectable abnormalities that were more similar to the axis I diagnosed suicide group than to a living group. Both suicide groups were similar in the total number of past suicide attempts, the total number of individuals with an axis II disorder, and similar scores on measures of impulsive-aggressive behaviors.

Conclusions: These findings suggest that most of the individuals who committed suicide and appeared psychiatrically normal after a psychological autopsy may probably have an underlying psychiatric process that the psychological autopsy method, as commonly carried out, failed to detect.

\section{Background}

Suicide is an important public health problem, ranking among the top ten causes of death for individuals of all ages in most developed countries [1]. Studies of suicide have identified a number of risk factors for suicide completion. These include previous suicide attempts, male sex, family history of suicide, and presence of psychiatric problems [1-3]. Of these factors, psychiatric morbidity is one of the most important predictors of suicide $[4,5]$.
The standard method to assess psychopathology in suicide completers is the psychological autopsy [6]. This is a proxy-based interview process with best informants on the deceased that investigates, more recently, by means of structured diagnostic procedures, psychopathology or other information of interest. Approximately $90 \%$ of suicide cases have a detectable psychiatric disorder in psychological autopsy studies, most of which have been focusing on the presence of axis I disorders [7-9]. It is unclear, however, whether the remaining ten per cent of 
suicide cases had no major psychopathology or whether they had more subtle psychopathological alterations to which the psychological autopsy method may not have been sensitive enough. We hypothesized that if the latter were true, suicide cases without a detectable axis I diagnosis in psychological autopsy assessments would have more in common with suicide cases that do meet criteria for an axis I diagnosis than with controls who do not, on behavioral and psychiatric measures other than those used to assess axis I diagnoses.

\section{Methods}

Subjects were identified as part of an ongoing collaboration with the Coroner's Office of the Montreal Central Morgue, where suicide cases were recruited consecutively. After written informed consent was obtained from the next of kin, a total of 168 suicide cases were assessed by means of psychological autopsy procedures as outlined elsewhere [5,10]. Briefly, informants best-acquainted with the deceased were interviewed using the SCID I [11] or KSADS [12], SCID II [13], and adapted instruments to measure related personality traits. These included the Barratt Impulsivity Scale version 11 (BIS-11) [14], the BussDurkee Hostility Inventory (BDHI) [15], the BrownGoodwin History of Aggression (BGHA) [16] and the Temperament and Character Inventory (TCI) [17]. A vignette containing a summary of all relevant clinical information was then reviewed by a panel of psychiatrist for best-estimate consensus diagnoses using DSM-IV criteria.

The cases without an axis I disorder (NAIS) were age and gender matched ( $+/-3$ years) to at least three suicide cases who had an axis 1 disorder (AIS). In addition to the AIS comparison group, we compared the NAIS cases to a total of 110 age and gender-matched living comparison subjects (LS), 28 of which had completed axis II assessments and the remaining subjects were assessed for personality traits that are believed to mediate suicidal behavior.

Two tailed t-tests, $\chi^{2}$ and one-way ANOVAs were performed using SPSS. Fisher exact test and Odds ratio were carried out when applicable. $N$ may vary in the different analyses carried out as individual measures may not be available for all subjects.

\section{Results}

Of the 168 suicide completers, 16 suicide cases (15 M: 1 F) did not meet criteria for an axis I disorder. This percentage $(9.5 \%)$ is consistent with expectations based on previous studies [18]. Fifty-two (49 M: 3 F) suicide cases were included in the AIS group. Mean ages were $35.7 \pm 13.7$ and $36.1 \pm 13.1$ years respectively for the NAIS and for the AIS groups. In addition, a total of 110 living subjects (LS) aged $38.4 \pm 11.7$ years were used as a group reference and for comparisons with the suicides. All groups had similar age distribution $(P=0.75)$.

Table 1 lists relevant clinical information obtained in the psychological autopsies of the 16 NAIS cases included in this study, by means of open interviews carried out with informants. These interviews were particularly useful in the NA1S, but did not allow us to systematically obtain diagnostic information that could be compared between groups. It is interesting to note, nevertheless, that 4 subjects had a history of excessive gambling causing interpersonal and financial problems, suggesting pathological gambling (an axis I diagnosis not covered by the SADS nor the SCID I interview). Axis I diagnostic distribution in the AIS cases was similar to that seen in unselected suicide cases from our suicide series [10]. Five (31\%) of the NAIS cases and $23(44 \%)$ of the AIS group had an axis II disor$\operatorname{der}(\mathrm{OR}=0.57 \mathrm{CI}: 0.15-2.15 ; P=0.35)$, whereas none of the LS subjects had an axis II diagnosis (NAIS vs LS: Fisher $P=0.01)$. Nine (56\%) NAIS cases had previously attempted suicide, which was similar to the proportion observed among the AIS group ( $\mathrm{N}=26$ or $50 \%)(\mathrm{OR}=$ 1.29 CI: $0.36-4.59: P=0.66$ ), but not among LS subjects, none of whom had attempted suicide (NAIS vs LS: Fisher $P<0.01)$.

Suicide completers are thought to be more impulsive [19] and more aggressive $[10,20,21]$ than individuals who do not commit suicide. NAIS, AIS and LS were different in total measures of aggression according to the BDHI $(\mathrm{F}=$ $4.69,2 \mathrm{df}, \mathrm{P}=0.01)$. Both NAIS cases $(35 \pm 11.7)(P=$ $0.07)$ and AIS (32.27 \pm 12.0$)$ were more aggressive according to BDHI measures than LS subjects $(26.5 \pm 11.4)(P=$ 0.04 ). The irritability, resentment and guilt subscales primarily accounted for this difference. No differences were found between groups on the BIS or on the BGLH.

\section{Discussion}

In this study we investigated psychopathology on subjects who do not present an axis I disorder according to psychological autopsy assessments using standardized instrument procedures. We found that subjects who appear psychiatrically normal are more similar to suicide cases meeting criteria for an axis I than to living normal controls in measures of psychopathology other than axis I. Moreover, we found evidence that axis I conditions besides those commonly assessed for by standard diagnostic instruments, such as pathological gambling, may be present in suicide cases who apparently do not have an axis I disorder. These results suggest that most of the individuals who committed suicide, and appeared psychiatrically normal after a psychological autopsy, may probably have either an axis I disorder that was not detected by the psychological autopsy process and/or an axis II disorder, and therefore, pointing to reduced sensitivity of the commonly 
Table I: Demographic and relevant clinical features of suicide completers that do not meet criteria for an axis I psychiatric disorder according to structured clinical interviews.

\begin{tabular}{|c|c|c|}
\hline Age of NAIS subjects & Gender & Relevant clinical features \\
\hline 18 & M & Personality disorder NOS, history of suicide attempt \\
\hline 20 & M & History of suicide attempt \\
\hline 20 & M & Passive-aggressive personality disorder, hypothyroidism, history of suicide attempt \\
\hline 20 & M & I/5 school days spent in bed at the age of 16 . History of suicidal ideation \\
\hline 28 & M & Hospitalized at 17 for suicide attempt by hanging \\
\hline 28 & M & nil \\
\hline 31 & M & HIV +, unaccepted homosexuality \\
\hline 33 & M & Schizoid personality disorder, history of suicide attempt \\
\hline 33 & M & History of excessive gambling and suicide attempt \\
\hline 38 & $\mathrm{~F}$ & Diagnosed with fibromyalagia \\
\hline 40 & M & $\mathrm{HIV+}$, unaccepted homosexuality, history of 2 suicide attempts \\
\hline 45 & M & History of excessive gambling and 2 suicide attempts \\
\hline 52 & M & Obsessive-compulsive personality disorder \\
\hline 54 & M & Antisocial personality disorder \\
\hline 55 & M & History of excessive gambling and suicide attempt \\
\hline 59 & M & History of excessive gambling \\
\hline
\end{tabular}

used psychological autopsy procedures that have been indicating a rate of approximately $10 \%$ of seemingly normal suicide completers. Our results are consistent with data from the literature. Brent et al [22] investigated demographic and psychosocial risk factors for suicide in 7 suicide victims with no apparent psychopathology and compared them to 60 suicide victims with a definite or probable psychiatric disorder, as well as to 38 community controls with no psychiatric disorder. This study was carried out in adolescent suicides, but it is to our knowledge the only other study that investigated suicides without an axis I diagnosis. They also found results suggesting that suicides without psychopathology had more in common with diagnosed suicides than with community controls.

Possible issues affecting the sensitivity and specificity of the psychological autopsy include factors related to the method of assessment per se and limitations of the proxybased interview procedure [6]. For instance, the inability of our psychological autopsy interviews to detect pathological gambling is an example of the first type of problem. Accordingly, there are several reports suggesting a link between suicidal behavior and gambling problems [23-27]. As such, it would have been interesting to assess systematically for the presence of pathological gambling in psychological autopsy studies of suicide, and more specifically, in our A1S group. Because this was not carried out systematically, we cannot directly compare rates of pathological gambling between the NAIS and AIS groups.

Recall biases and/or imprecise information are among the limitations of assessing psychopathology through informants [28-32]. Accordingly, because of the nature of the bereavement process, some relatives may tend to distort the information about a deceased relative. In addition, because of the social withdrawal that some suicides may present prior to death, some informants may not have precise information about the psychiatric condition of the deceased prior to death $[6,30]$. It is interesting to note, though, that of the nine NAIS cases who had previously attempted suicide, four had made attempts at a period two years or longer before their death. This suggests that psychopathology in these cases was not of recent onset. Nevertheless, the informant was not aware of its presence. This could be explained by sub-threshold psychopathology or recall bias.

The major limitation of this study is the small number of subjects included in the NAIS group. However, it is difficult to obtain a larger group of suicide completers without an axis I disorder, given that they represent only approximately $10 \%$ of all suicide completers. Nevertheless, in spite of the small numbers, we were able to detect differences between the groups that supported out hypothesis.

This study demonstrates the presence of pathology in the form of an axis II disorder or a previous suicide attempt in suicide completers without an axis I diagnosis. The findings suggest that probably all suicide cases are associated with some form of a psychiatric disorder. Future investigations of suicide completers without an axis I disorder may contribute to improvements in diagnostic methods and to our understanding of the association between mental disorders and suicide. 
Table 2: Measures of impulsive and aggressive behavior according to different instruments in suicides with and without an axis I diagnosis and in normal controls

\begin{tabular}{lcccccccc}
\hline Instrument & \multicolumn{2}{c}{ NAIS } & & & AIS & LS & P \\
\cline { 2 - 8 } & Mean & SD & Mean & SD & Mean & SD \\
\hline BIS & 61.7 & 12.3 & 63.4 & 13.8 & 60.5 & 10.8 & 0.577 \\
BGHA & 4.9 & 3.6 & 10.5 & 11.0 & 6.8 & 8.1 & 0.125 \\
BDHI & 35.0 & 11.7 & 32.3 & 12.0 & 26.4 & 11.4 & $0.011^{*}$ \\
TCl-NS & 20.6 & 6.5 & 20.4 & 6.6 & 17.5 & 6.38 & 0.088 \\
\hline
\end{tabular}

NS: Novelty Seeking. Tukey post-hoc comparison

\section{Competing interests}

None declared.

\section{Authors' contributions}

CE participated in the design of the study, analysis and preparation of the manuscript, $\mathrm{AL}, \mathrm{AL}, \mathrm{MS}$ and MT participated in data collection and preparation of the manuscript, GT conceived of the study, and participated in its design and coordination. All authors read and approved the final manuscript.

\section{References}

I. Diekstra RF: The epidemiology of suicide and parasuicide. Acta Psychiatr Scand 1993, 37 I (Suppl):9-20.

2. Turecki G: Suicidal Behavior: Is There a Genetic Predisposition? Bipolar Disorders 200I, 3:335-349.

3. Angst F, Stassen HH, Clayton PJ, Angst J: Mortality of patients with mood disorders: follow-up over 34-38 years. J Affect Disord 2002, 68: 167-8I.

4. Barraclough B, Hughes J: Mental Illness and suicide. In: Suicide: Clinical and Epidemiological Studies New York: Croom Helm; 1987:8-36.

5. Lesage AD, Boyer R, Grunberg F, Vanier C, Morissette R, MenardButeau C, Loyer M: Suicide and Mental Disorders: A Case-Control Study of Young Men. American Journal of Psychiatry 1994, I 5 I:1063-1068.

6. Hawton K, Appleby L, Platt S, Foster T, Cooper J, Malmberg A, Simkin $\mathrm{S}$ : The psychological autopsy approach to studying suicide: a review of methodological issues. J Affect Disord 1998, 50:269-76.

7. Cheng AT, Chen TH, Chen CC, Jenkins R: Psychosocial and psychiatric risk factors for suicide. Case-control psychological autopsy study. Br J Psychiatry 2000, 177:360-5.

8. Vijayakumar L, Rajkumar S: Are risk factors for suicide universal? A case-control study in India [see comments]. Acta Psychiatr Scand 1999, 99:407-II.

9. Henriksson MM, Hillevi MA, Marttunen MJ, Heikkinen ME, Isometsa ET, Kuoppasalmi KI, Lonnqvist JK: Mental disorders and comorbidity in suicide. American Journal of Psychiatry 1993, 150:935-940.

10. Kim C, Lesage A, Seguin M, Lipp O, Vanier C, Turecki G: Patterns of comorbidity in male suicide completers. Psychol Med 2003, 33:1299-1309.

II. Spitzer RL, Williams JB, Gibbon M, First MB: The Structured Clinical Interview for DSM-III-R (SCID). I: History, rationale, and description. Arch Gen Psychiatry 1992, 49:624-9.

12. Chambers WJ, Puig-Antich J, Hirsch M, Paez P, Ambrosini PJ, Tabrizi MA, Davies M: The assessment of affective disorders in children and adolescents by semistructured interview. Testretest reliability of the schedule for affective disorders and schizophrenia for school-age children, present episode version. Arch Gen Psychiatry 1985, 42:696-702.

13. First MB, Spitzer RL, Gibbon M, Williams JBW: The structured clinical interview for DSM-III-R personality disorders (SCIDII). Part I: Description. Journal of Personality Disorders 1995, 9:2.
14. Barratt E: Barratt Impulsiveness Scale. 1959.

15. Buss AH, Durkee A: An Inventory for Assessing Diferent Kinds of Hostility. Journal of Consulting Psychology 1957, 2 I :343-349.

16. Brown GL, Goodwin FK: Human aggression and suicide. Suicide Life Threat Behav 1986, 16:223-43.

17. Cloninger CR, Przybeck TR, Svrakic DM, Wetzel RD: The temperament and character inventory ( $\mathrm{TCl})$ : A guide to its development and use. St. Louis, Missouri: Center for Psychobiology of Personality, Washington University; 1994.

18. Cavanagh JT, Carson AJ, Sharpe M, Lawrie SM: Psychological autopsy studies of suicide: a systematic review. Psychol Med 2003, 33:395-405.

19. Maser JD, Akiskal HS, Schettler P, Scheftner W, Mueller T, Endicott J, Solomon D, Clayton P: Can temperament identify affectively ill patients who engage in lethal or near-lethal suicidal behavior? A I4-year prospective study. Suicide Life Threat Behav 2002, 32: $10-32$.

20. Romanov K, Hatakka M, Keskinen E, Laaksonen H, Kaprio J, Rose RJ, Koskenvuo M: Self-reported hostility and suicidal acts, accidents, and accidental deaths: a prospective study of 21,443 adults aged 25 to 59. Psychosom Med 1994, 56:328-36.

21. Conner KR, Duberstein PR, Conwell Y, Seidlitz L, Caine ED: Psychological vulnerability to completed suicide: a review of empirical studies. Suicide Life Threat Behav 200I, 3 I:367-85.

22. Brent DA, Perper J, Moritz G, Baugher M, Allman C: Suicide in adolescents with no apparent psychopathology. J Am Acad Child Adolesc Psychiatry 1993, 32:494-500.

23. Kausch O: Suicide attempts among veterans seeking treatment for pathological gambling. J Clin Psychiatry 2003, 64:1031-8.

24. Maccallum F, Blaszczynski A: Pathological gambling and suicidality: an analysis of severity and lethality. Suicide Life Threat Behav 2003, 33:88-98.

25. Newman SC, Thompson AH: A population-based study of the association between pathological gambling and attempted suicide. Suicide Life Threat Behav 2003, 33:80-7.

26. Petry NM, Kiluk BD: Suicidal ideation and suicide attempts in treatment-seeking pathological gamblers. J Nerv Ment Dis 2002, 190:462-9.

27. Blaszczynski A, Farrell E: A Case Series of 44 Completed Gambling-Related Suicides. J Gambl Stud 1998, 14:93-109.

28. Kelly TM, Mann Jl: Validity of DSM-III-R diagnosis by psychological autopsy: a comparison with clinician ante-mortem diagnosis. Acta Psychiatr Scand 1996, 94:337-43.

29. Brent DA, Perper JA, Moritz G, Allman CJ, Roth C, Schweers J, Balach $L$ : The validity of diagnoses obtained through the psychological autopsy procedure in adolescent suicide victims: use of family history. Acta Psychiatr Scand 1993, 87: I I 8-22.

30. Beskow J, Runeson B, Asgard U: Psychological autopsies: methods and ethics. Suicide Life Threat Behav 1990, 20:307-23.

31. Conner KR, Conwell Y, Duberstein PR: The validity of proxybased data in suicide research: a study of patients 50 years of age and older who attempted suicide. I. Psychiatric diagnoses. Acta Psychiatr Scand 200I, 104:452-7.

32. Conner KR, Conwell Y, Duberstein PR: The validity of proxybased data in suicide research: a study of patients $\mathbf{5 0}$ years of age and older who attempted suicide. II. Life events, social 
support and suicidal behavior. Acta Psychiatr Scand 200I, 104:452-7.

\section{Pre-publication history}

The pre-publication history for this paper can be accessed here:

http://www.biomedcentral.com/1471-244X/4/7/prepub

Publish with Bio Med Central and every scientist can read your work free of charge

"BioMed Central will be the most significant development for disseminating the results of biomedical research in our lifetime. " Sir Paul Nurse, Cancer Research UK

Your research papers will be:

- available free of charge to the entire biomedical community

- peer reviewed and published immediately upon acceptance

- cited in PubMed and archived on PubMed Central

- yours - you keep the copyright 